\title{
Potential impacts of future land use and climate change on the Red List status of the Proteaceae in the Cape Floristic Region, South Africa
}

\author{
BASTIAN BOMHARD*†, DAVID M. RICHARDSON $\ddagger \S$, JOHN S. DONALDSON*, GREG O. \\ HUGHES*, GUY F. MIDGLEY*, DOMITILLA C. RAIMONDO*, ANTHONYG. REBELO*, \\ MATHIEU ROUGET* and WILFRIED THUILLER* \\ *Kirstenbosch Research Centre, South African National Biodiversity Institute, Private Bag X7, Claremont 7735, South Africa, \\ $\dagger$ Percy FitzPatrick Institute of African Ornithology, University of Cape Town, Private Bag, Rondebosch 7701, South Africa, $\ddagger$ Centre \\ for Invasion Biology, University of Stellenbosch, Private Bag X1, Matieland 7602, South Africa, §Leslie Hill Institute for Plant \\ Conservation, University of Cape Town, Private Bag, Rondebosch 7701, South Africa, $\uparrow$ Center for Applied Biodiversity Science, \\ Conservation International, 1919 M Street, NW Suite 600, Washington DC 20036, USA
}

\begin{abstract}
Using spatial predictions of future threats to biodiversity, we assessed for the first time the relative potential impacts of future land use and climate change on the threat status of plant species. We thus estimated how many taxa could be affected by future threats that are usually not included in current IUCN Red List assessments. Here, we computed the Red List status including future threats of 227 Proteaceae taxa endemic to the Cape Floristic Region, South Africa, and compared this with their Red List status excluding future threats. We developed eight different land use and climate change scenarios for the year 2020, providing a range of best- to worst-case scenarios. Four scenarios include only the effects of future land use change, while the other four also include the impacts of projected anthropogenic climate change (HadCM2 IS92a GGa), using niche-based models. Up to a third of the 227 Proteaceae taxa are uplisted (become more threatened) by up to three threat categories if future threats as predicted for $\mathbf{2 0 2 0}$ are included, and the proportion of threatened Proteaceae taxa rises on average by 9\% (range 2-16\%), depending on the scenario. With increasing severity of the scenarios, the proportion of Critically Endangered taxa increases from about 1\% to $7 \%$ and almost $2 \%$ of the 227 Proteaceae taxa become Extinct because of climate change. Overall, climate change has the most severe effects on the Proteaceae, but land use change also severely affects some taxa. Most of the threatened taxa occur in low-lying coastal areas, but the proportion of threatened taxa changes considerably in inland mountain areas if future threats are included. Our approach gives important insights into how, where and when future threats could affect species persistence and can in a sense be seen as a test of the value of planned interventions for conservation.
\end{abstract}

Key words: biodiversity conservation, Cape Floristic Region, climate change, extinction risk, IUCN Red List, land use change, niche-based models, Proteaceae, threatened species

Received 1 November 2004; revised version received 15 March 2005 and accepted 22 March 2005

\section{Introduction}

Land use and climate change are considered to be the major drivers of global biodiversity change in terrestrial ecosystems in the near future (Sala et al., 2000). Habitat

Correspondence: Bastian Bomhard, Am Brucher Haeuschen 79, 42109 Wuppertal, Germany. tel. + 49 (0)202 7052020,

e-mail: BastianBomhard@yahoo.com destruction and degradation, mostly because of agriculture, invasive alien species and urbanization are the main past and present causes of species endangerment and extinction (Czech \& Krausman, 1997; Wilcove et al., 1998). However, anthropogenic climate change increasingly imposes a major additional threat, causing species range shifts and losses, population declines and extinctions (Hughes, 2000; McCarty, 2001; Parmesan \& Yohe, 2003; Root et al., 2003). 
Similarly, in the Cape Floristic Region (CFR), a global biodiversity hotspot comprising one of the world's six floristic kingdoms (Cowling et al., 1997; Myers et al., 2000), habitat transformation through agriculture, invasive alien plants and urbanization has been identified as a major past, present and future threat to biodiversity (Rebelo, 1992; Richardson et al., 1996; Rouget et al., 2003c; Latimer et al., 2004). In addition, anthropogenic climate change is likely to be a major future threat to the biodiversity in the CFR (Rutherford et al., 1999; Midgley et al., 2002, 2003).

The threat status of the world's species is typically assessed based on what we currently know about species distributions, population sizes and population declines. The IUCN has produced standardized Red List criteria that are the most commonly used tools to identify and classify species of conservation concern (Lamoreux et al., 2003). Although the criteria allow for future threats to be included in IUCN Red List assessments (IUCN, 2001, 2003), lack of data or uncertainty about future threats means that most assessments are based on current species distributions and population sizes or past population declines. The impact of future threats, particularly threats such as climate change, on the threat status of most species remains largely unknown (Burgman, 2002). It is, therefore, difficult to determine whether the inclusion of future threats would result in a substantial change in the number and Red List status of threatened species, the types of species that are threatened or the distribution of these species, with concomitant implications for conservation planning and action.

This study assesses how the threat status of plant species could change if environmental conditions predicted by land use and climate change models for the year 2020 are incorporated into a Red List assessment. Our aim is not to test the IUCN Red List Categories and Criteria, but to estimate how many species are likely to be affected by future land use and climate change, threats that are usually not included in current IUCN Red List assessments. Such a study provides a first estimation of the relative importance of future threats for species conservation efforts.

The impact of future land use change and, recently, climate change has been translated into crude estimates of extinction risk elsewhere (Gaston et al., 2003; Thomas et al., 2004). However, to the best of our knowledge, nobody has yet calculated a Red List status for a set of species, taking into account the combined impacts of land use and climate change in the near future, and compared it with their current Red List status. In the CFR, high-resolution species distribution data from the Protea Atlas Project (Rebelo, 2001), spatial predictions of land use change (Rouget et al., 2003c) and spatial, species-specific predictions of climate change (Midgley et al., 2003) provide the opportunity to assess the potential impacts of future land use and climate change on the Red List status of the Proteaceae, a characteristic plant family of the predominant fynbos biome in the CFR.

Here, we compute the Red List status of 227 Proteaceae taxa endemic to the CFR, for which species-specific climate change predictions were available for 2020, including future threats, and compare this with their Red List status excluding future threats. The timeframe of this study corresponds to that of the Cape Action for People and the Environment programme (http://capeaction.org.za) that seeks to conserve the biodiversity of the CFR (Cowling et al., 2003). We developed eight different land use and climate change scenarios for the year 2020. We consider these to provide a reasonable range of best- to worst-case scenarios of environmental conditions for the near future in the CFR. Four scenarios include only the effects of habitat transformation and, indirectly, habitat conservation, ranging from best- to worst-case estimates of these parameters (White et al., 1997). An additional four scenarios also include the impacts of climate change (Midgley et al., 2003).

Specifically we ask: How does future land use and climate change impact on the number and Red List status of threatened Proteaceae in the CFR, what are their relative potential impacts and which taxa face the highest threat status or largest changes in their threat status? Furthermore, we assess whether or not land use and climate change impact differently on taxa from different regions and altitudes as has been shown elsewhere (Rebelo, 1992; Richardson et al., 1996; Midgley et al., 2002, 2003). Finally, we identify areas in which the number of threatened taxa increases because of future land use and climate change as projected here - information potentially useful for proactive conservation planning and action.

\section{Materials and methods}

\section{Study area}

The CFR covers an area of approximately $87000 \mathrm{~km}^{2}$ at the southern tip of Africa (Fig. 1) and contains some 9030 vascular plant species, of which nearly $70 \%$ are endemic (Goldblatt \& Manning, 2002). Fynbos, the predominant vegetation type in the CFR, is an evergreen, fire-prone shrubland mainly characterized by three plant families: Proteaceae, Ericaceae and Restionaceae (Cowling et al., 1997). 


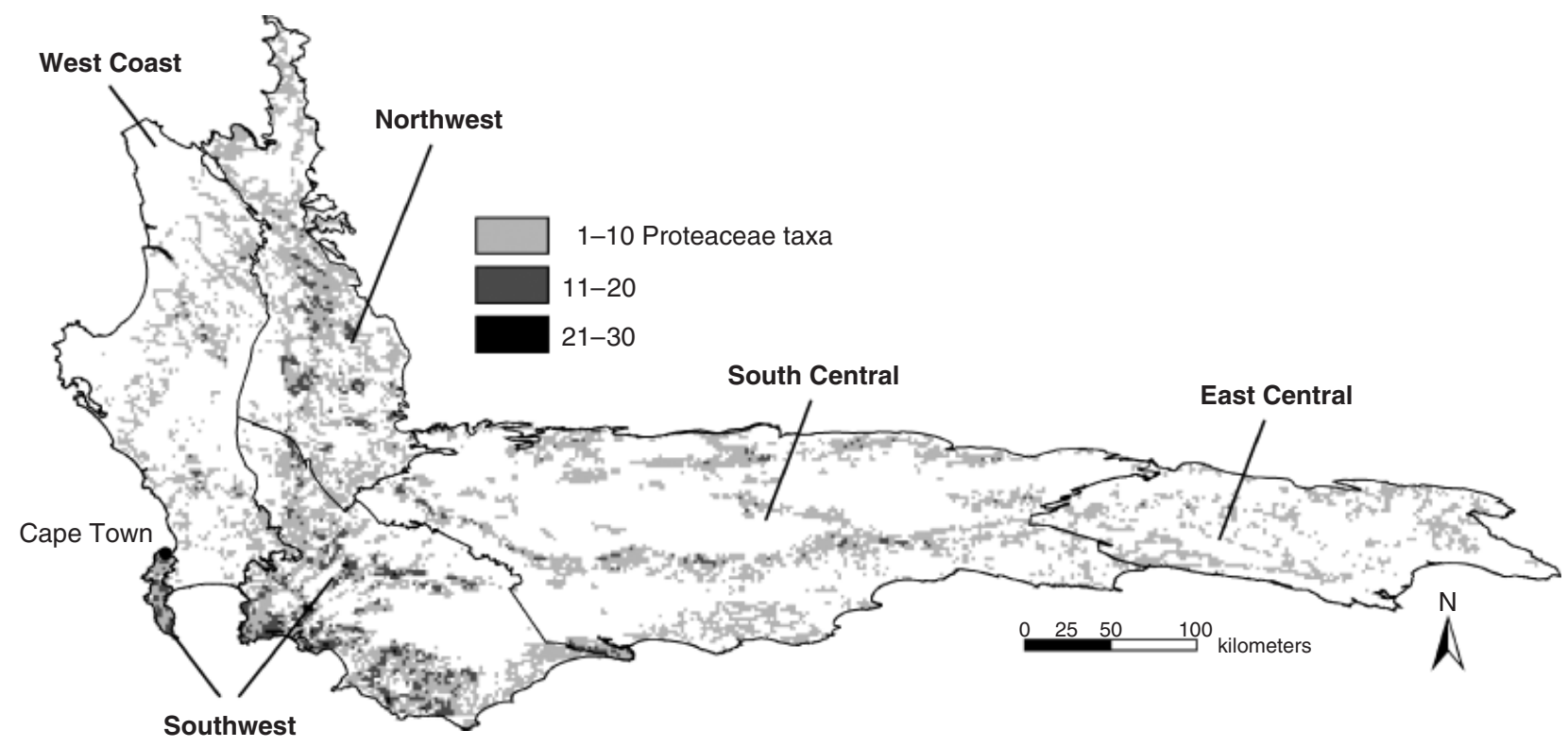

Fig. 1 South Africa's Cape Floristic Region showing phytogeographic regions and species richness summarized per 1 min grid cell $\left(2.9 \mathrm{~km}^{2}\right)$, as recorded by the Protea Atlas Project in October 2003, for the 227 Proteaceae taxa considered in this study.

\section{Scenarios}

Eight different land use and climate change scenarios were developed for 2020 (Fig. 2). Four scenarios, labelled $-\mathrm{CC} 1$ to $-\mathrm{CC} 4$, consider only the effects of habitat transformation and, indirectly, habitat conservation, ranging from best- to worst-case estimates of these parameters. Similar in their consideration of land use change, an additional four scenarios, labelled + CC1 to + CC4, include the impacts of climate change on species distributions based on a single climate change scenario (HadCM2 IS92a GGa). For the Red List assessment excluding and including future threats, information on species distributions and habitat conservation and transformation was used as follows.

\section{Current and future species distributions}

Current species distributions were obtained from the South African National Biodiversity Institute's (SANBI) Protea Atlas Project (http://protea.worldonline.co.za). This is one of the most comprehensive species distribution data sets in Africa with relatively low levels of sampling bias (Lombard et al., 2003). It currently contains some 250000 records for 377 species, subspecies and varieties (hereafter species or taxa) of Proteaceae (Rebelo, 2001). For our Red List assessment at a regional level (Gärdenfors et al., 2001), all 227 Proteaceae taxa endemic to the CFR for which there were species-specific climate change predictions avail- able were selected, as recorded by the Protea Atlas Project in October 2003 (Fig. 1). They represent terminal taxa - species, subspecies and varieties - of 11 genera (nomenclature follows Rebelo, 2001). All taxa were assigned to one of five phytogeographic regions (Fig. 1) (Goldblatt \& Manning, 2002) and to one of four altitudinal zones based on where they are predominantly recorded at present.

Potential current and future species distributions for 2020 were obtained from SANBIs Climate Change Research Group (Midgley et al., 2003). These were modelled at a $1 \mathrm{~min}$ scale using Generalized Additive Models (GAM), which determine the environmental limits of an entity with a given spatial distribution by matching its distribution to surfaces of environmental parameters (Yee \& Mitchell, 1991). Five bioclimatic and three edaphic variables, all considered critical to plant survival (Midgley et al., 2003), were used to build stepwise GAMs of environmental constraints for each species in S-Plus (MathSoft S-Plus Version 2000). Probability of occurrence from GAMs was mapped using ArcView software (ESRI ArcView Version 3.2). Then species-specific probability cut-off points were determined by maximizing jointly the percentage of presence and absence correctly predicted (Pearce \& Ferrier, 2000; Thuiller et al., 2003). Further details on bioclimatic modelling and its limitations are provided elsewhere (Pearson et al., 2004; Thuiller, 2004; Thuiller et al., 2004). Potential future species distributions for 2020 were derived using climate change projections 


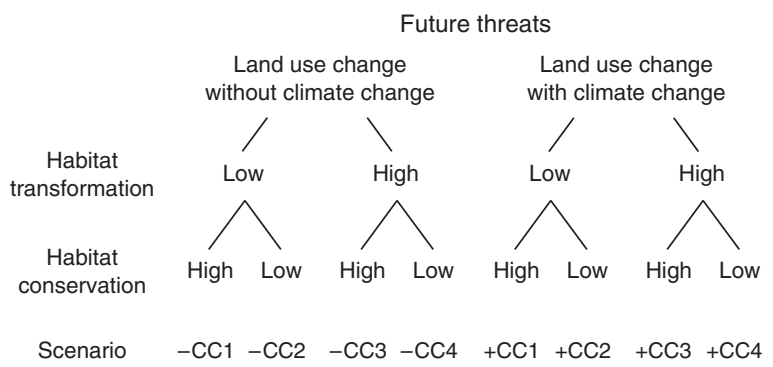

Fig. 2 Overview of the future scenarios and their labelling (scenarios increase in severity from left to right: $-\mathrm{CC}$ is without climate change; + CC is with climate change). The scenarios $-\mathrm{CC} 1$ to $-\mathrm{CC} 4$ and $+\mathrm{CC} 1$ to $+\mathrm{CC} 4$ are similar in their consideration of land use change, but the latter include the impacts of climate change on species distributions based on a single climate change scenario (HadCM2 IS92a GGa).

originating from the Global Circulation Model HadCM2 of the UK Hadley Centre for Climate Prediction and Research for southern Africa for 2050. The applied HadCM2 IS92a GGa scenario of the model predicts an average increase of $0.7^{\circ} \mathrm{C}\left( \pm 0.1^{\circ} \mathrm{C}\right.$, range $0.5-1.0^{\circ} \mathrm{C}$ ) in mean annual temperature and an average decrease of $41 \mathrm{~mm}( \pm 25 \mathrm{~mm}$, range $7-295 \mathrm{~mm})$ in mean annual precipitation for the CFR for 2020 assuming a constant rate of climate change through to 2050.

Future species distributions for the Red List assessment including climate change impacts were finally determined by deleting those records from the original species distribution data set that are outside the modelled future ranges. This approach involves two simplifying assumptions, which may introduce some uncertainty. Firstly, all plants that currently occur outside the modelled future ranges will be extinct by 2020. As most Proteaceae are relatively long-lived species with life spans in excess of 15 years (Cowling et al., 1997; Rebelo, 2001) this is unlikely. However, we assumed that viable populations would not persist permanently outside the potential future ranges, and we thus treated plants in areas where they are eventually committed to extinction as extinct by 2020 . It is noteworthy that current species records may be outside the modelled future ranges because the affected areas become bioclimatically unsuitable or simply because the models are a poor fit to the data. We did, however, not attempt to correct for this. Secondly, we assumed that Proteaceae would not migrate into new areas, which will become bioclimatically suitable by 2020, because most of the Proteaceae are localized dispersers whose dispersal is closely linked to the fire cycle in the fynbos biome (Cowling et al., 1997; Rebelo, 2001). It is unlikely that, without human facilitation, significant migration will occur across the CFRs fragmented landscapes by 2020. According to the bioclimatic models for all the study taxa, $25.9 \%$ of the current species records are outside the modelled future ranges for 2020. While seven taxa do not lose any of their records, four taxa lose all of them.

\section{Current and future habitat conservation and transformation}

Information on current and future conservation areas (Fig. 3b, c) was used to identify areas that are unlikely to be affected by future habitat transformation. Our worst-case future conservation scenario assumes that the existing conservation area network remains unchanged until 2020. A Geographic Information Systems (GIS) layer of existing reserves was obtained from the Western Cape Nature Conservation Board's Conservation Planning Unit (http://cpu.uwc.ac.za). It includes statutory reserves such as national parks, provincial nature reserves and local authority reserves, as well as some nonstatutory reserves such as national heritage sites and private nature reserves (Rouget $e t$ al., 2003b). Our best-case future conservation scenario assumes that this existing conservation area network will be expanded by the successful implementation of three proposed megareserves before 2020 (Cowling et al., 1999; Younge, 2000). The proposed megareserves each cover between 400000 and 600000 ha of currently untransformed habitat, and extend across climatic, biotic and altitudinal gradients to alleviate future climate change impacts (Cowling et al., 1999; Younge, 2000). Their purpose is to protect areas extensive and diverse enough to maintain top predators, megaherbivores, natural fire regimes and other landscape-scale processes (Cowling et al., 1999; Younge, 2000). They will use a wide range of mechanisms including land use zoning, statutory and nonstatutory reserves to meet this purpose. For this study, we obtained GIS layers of the latest available, but still preliminary, outlines of the proposed Gouritz, Cederberg and Baviaanskloof megareserves from the Western Cape Nature Conservation Board's Conservation Planning Unit and Baviaanskloof Megareserve Project. The megareserves are expected to be implemented before 2020 (Younge, 2000), which corresponds to the timeframe of this study, and thus provide, together with the existing conservation areas, a first estimate for future habitat conservation in the CFR.

Information on current and future habitat transformation (Fig. 3a) was used as a surrogate for population reduction in the Red List assessment (IUCN, 2001, 2003). A GIS layer on current habitat transformation, defined as urbanized or cultivated areas (including forestry plantations) and medium- or high-density stands of invasive alien trees and shrubs (Rouget et al., 2003c), was provided by the Protea Atlas Project. 
It was originally derived from LANDSAT TM imagery captured in 1997 and 1998 (Lloyd et al., 1999; Rouget et al., 2003c).

Only currently untransformed habitat outside conservation areas can be transformed in the future because we assumed that management within all current and future conservation areas would prevent further habitat transformation. Best- and worst-case scenarios, considered to cover a realistic range of potential future land use change, were developed for future habitat transformation (Fig. 3a). Information on future habitat transformation was derived from $1 \mathrm{~min}$ grid layers $\left(2.9 \mathrm{~km}^{2}\right.$ cell size $)$ on future threats to biodiversity developed by Rouget et al. (2003c). They identified currently untransformed areas threatened by urbanization, using a simplistic rule-based modelling approach and currently untransformed areas threatened by agriculture and invasive alien trees and shrubs, using a statistical modelling approach. They classified all areas as follows: not threatened, moderately or highly threatened by urbanization; not threatened or threatened by agriculture and moderately or highly threatened by alien plant invasions (Rouget et al., 2003c).

Not all areas threatened by future habitat transformation will be transformed by 2020. Thus, it was necessary to identify areas most likely to be transformed in 2020 from the grid layers on future threats to biodiversity. We required simple selection rules that, based on expert knowledge, give a reasonable range of future transformation rates across the CFR. Given that, with the exception of some areas affected by urbanization, it is unlikely that a single threat will completely transform all the natural areas in a grid cell by 2020, we chose the following approach: For our high future habitat transformation scenario, we regarded an area as transformed in 2020 if it is threatened by at least two of the three different threats at any levels. For our low future habitat transformation scenario, we regarded an area as transformed in 2020 if it is threatened by at least two of the three different future threats at high levels (i.e. highly threatened by urbanization, threatened by agriculture and highly threatened by alien plant invasions). Depending on the scenario, all areas within the existing reserves and proposed megareserves were however considered untransformed in 2020, irrespective of future threat levels. Finally, the future trans- formed areas were combined with the current transformed areas to provide a single GIS layer of all areas transformed in 2020. We assumed that all currently transformed areas will still be transformed in 2020 (i.e. no restoration of currently transformed areas will take place).

At present $30.2 \%$ of the CFR is transformed and $13.5 \%$ is conserved (Rouget et al., 2003b,c). By 2020, between $31.5 \%$ and $36.7 \%$ will be transformed, and between $13.5 \%$ and $29.6 \%$ will be conserved, depending on the scenario. The best- and worst-case future habitat transformation scenarios translate into mean transformation rates of $0.07 \%$ and $0.33 \%$ of the CFR per year, respectively or an additional $2.0 \%$ and $9.4 \%$ of the currently remaining natural areas in the CFR being transformed by 2020 .

\section{Red List assessment excluding and including future threats}

We computed the Red List status for each taxon excluding and including future threats using a dBase IV programme (Borland Visual dBase Version 5.5a). We applied only criteria A and B of the new IUCN Red List Categories and Criteria, Version 3.1, which assess population reduction and geographic range parameters (Table 1) (IUCN, 2001, 2003). Criteria C, D and E were not applied because population size parameters and population viability analyses were not available for future scenarios. It should be noted that our simplistic, computer-based Red Listing approach is not comparable with a complete species-by-species IUCN Red List assessment.

Criterion A was applied using the proportion of transformed areas in a taxon's extent of occurrence (EOO) and area of occupancy (AOO) as a surrogate for population reduction (IUCN, 2001, 2003). The population reduction must be measured over the longer of 10 years or three generations (IUCN, 2001, 2003). The generation time of the Proteaceae is largely determined by the current fire cycle of about 10-30 years in most fynbos areas (Van Wilgen et al., 1992). For the assessment excluding future threats, we set the reference period for population reduction to 60 years (1940-2000), which corresponds to a period of extensive habitat transformation in the CFR (Hoffman, 1997). For the

Fig. 3 (a) Currently transformed areas and additionally transformed areas for the best- and worst-case future habitat transformation scenario. (b) Increase in number of threatened Proteaceae taxa of the Cape Floristic Region per 1 min grid cell $\left(2.9 \mathrm{~km}^{2}\right)$ if worst-case land use change as predicted for 2020 is included in the Red List assessment. Boundaries of existing reserves are shown in gray. (c) Increase in number of threatened Proteaceae taxa of the Cape Floristic Region per $1 \mathrm{~min}$ grid cell $\left(2.9 \mathrm{~km}^{2}\right)$ if worst-case land use and climate change as predicted for 2020 is included in the Red List assessment. Boundaries of existing reserves and proposed megareserves are shown in gray. 
assessment including future threats, we had to extend the reference period to 80 years (1940-2020), because detailed spatiotemporal information on the history of habitat transformation is lacking. Criterion B was applied using a threshold of $20 \%$ transformed areas within a taxon's geographic range as an indicator of

(a)

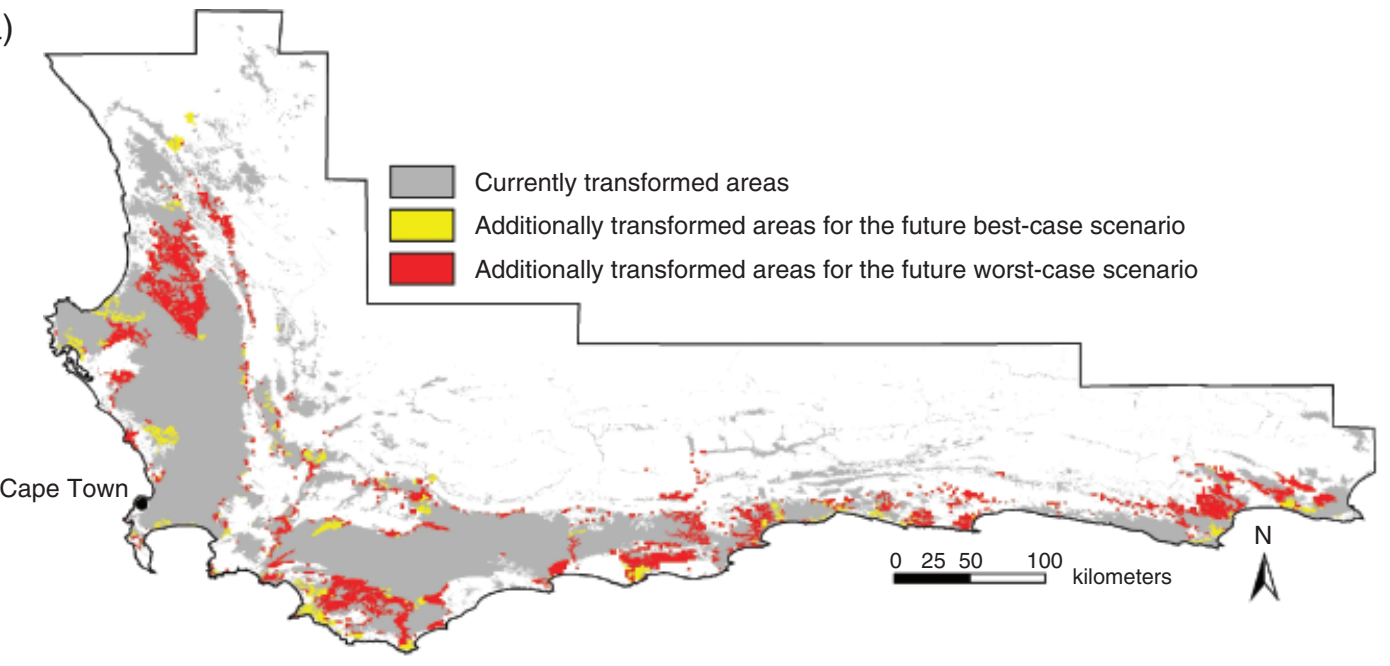

(b)

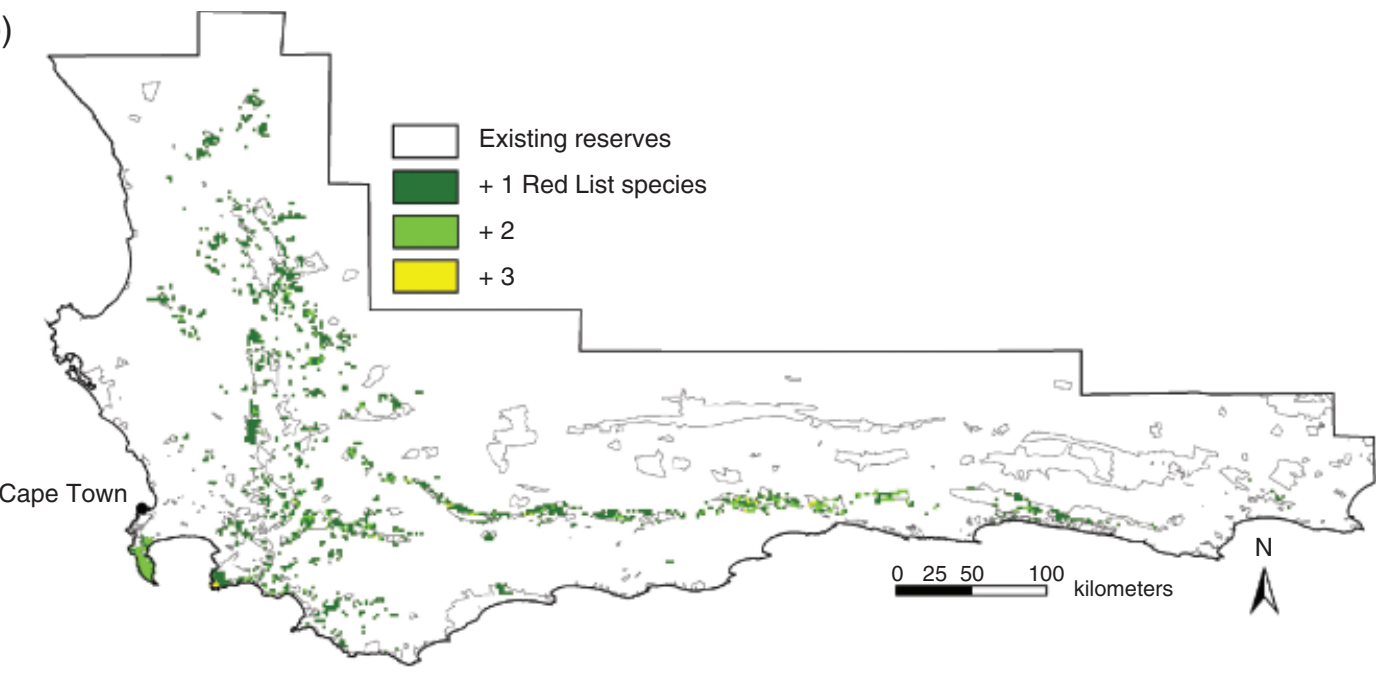

(c)

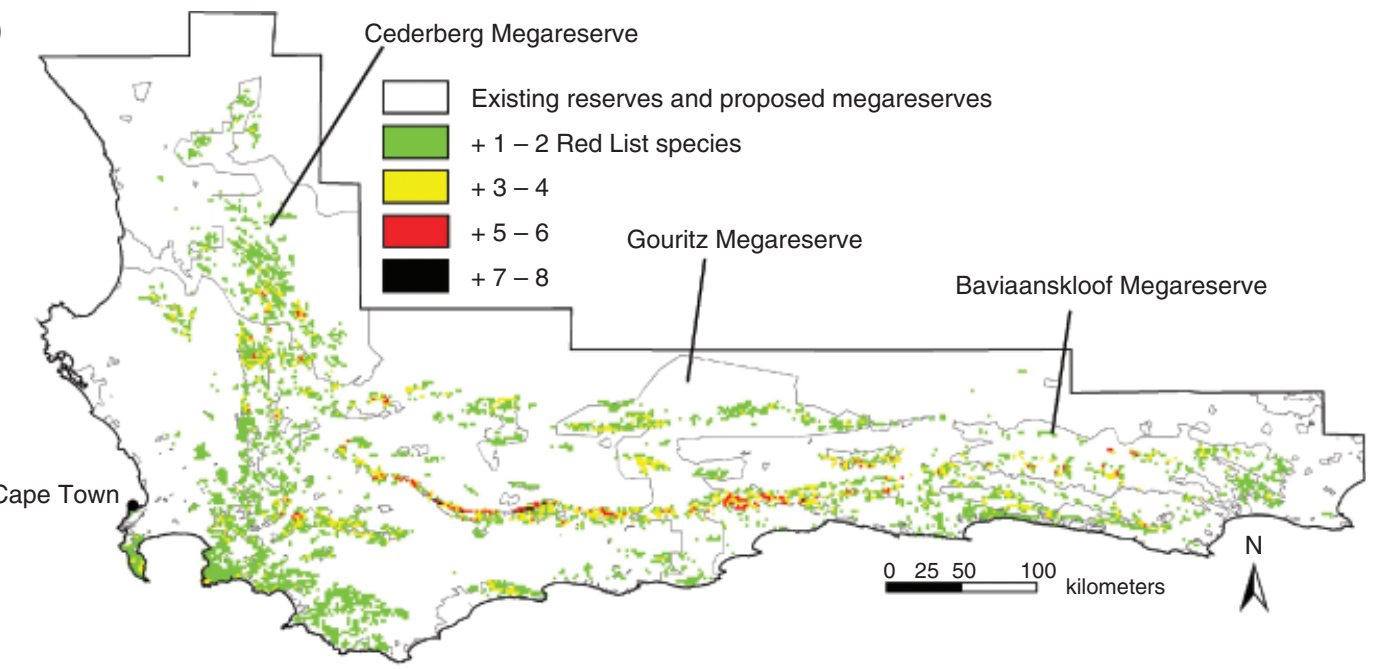

(C) 2005 Blackwell Publishing Ltd, Global Change Biology, 11, 1452-1468 
Table 1 Overview of the Red List criteria used to classify 227 Proteaceae taxa of the Cape Floristic Region into the Red List categories Critically Endangered (CR), Endangered (EN) and Vulnerable (VU) excluding and/or including future threats in the Red List assessment

\begin{tabular}{|c|c|c|c|}
\hline & CR & EN & VU \\
\hline \multicolumn{4}{|l|}{ (A) Population reduction } \\
\hline \multicolumn{4}{|l|}{ Excluding future threats: } \\
\hline $\begin{array}{l}\text { A2. Population reduction estimated } \\
\text { for the past based on (c) a decline in } \\
\text { AOO or EOO estimated from ca. } \\
1940 \text { to } 2000\end{array}$ & $>80 \%$ transformed & $\begin{array}{l}>50 \% \\
\text { transformed }\end{array}$ & $\begin{array}{l}>30 \% \\
\text { transformed }\end{array}$ \\
\hline \multicolumn{4}{|l|}{ Including future threats: } \\
\hline $\begin{array}{l}\text { A3. Population reduction projected } \\
\text { for the future based on (c) a decline } \\
\text { in AOO or EOO projected from } 2000 \\
\text { to } 2020\end{array}$ & $>80 \%$ range loss & $\begin{array}{l}>50 \% \text { range } \\
\text { loss }\end{array}$ & $\begin{array}{l}>30 \% \text { range } \\
\text { loss }\end{array}$ \\
\hline $\begin{array}{l}\text { A4. Population reduction estimated } \\
\text { for the past and projected for the } \\
\text { future based on (c) a decline in AOO } \\
\text { or EOO estimated and projected } \\
\text { from ca. } 1940 \text { to } 2020\end{array}$ & $>80 \%$ transformed & $\begin{array}{l}>50 \% \\
\text { transformed }\end{array}$ & $\begin{array}{l}>30 \% \\
\text { transformed }\end{array}$ \\
\hline \multicolumn{4}{|l|}{ (B) Geographic range } \\
\hline \multicolumn{4}{|l|}{ Excluding and including future threats: } \\
\hline B1. Either EOO or & $<100 \mathrm{~km}^{2}$ & $<5000 \mathrm{~km}^{2}$ & $<20000 \mathrm{~km}^{2}$ \\
\hline B2. $\mathrm{AOO}$ & $<10 \mathrm{~km}^{2}$ & $<500 \mathrm{~km}^{2}$ & $<2000 \mathrm{~km}^{2}$ \\
\hline \multicolumn{4}{|l|}{ and 2 of the following 3 : } \\
\hline (a) Number of locations (cells) & $=1$ & $\leq 5$ & $\leq 10$ \\
\hline (b ii) Continuing decline in (i) & $>20 \%$ transformed & $>20 \%$ & $>20 \%$ \\
\hline EOO or (ii) $\mathrm{AOO}$ & & transformed & transformed \\
\hline $\begin{array}{l}\text { (c iv) Extreme fluctuations in } \\
\text { number of mature individuals }\end{array}$ & \multicolumn{3}{|c|}{ Assumed for reseeders but not for resprouters } \\
\hline
\end{tabular}

AOO is area of occupancy and EOO is extent of occurrence (IUCN, 2001, 2003).

continuing population decline. This threshold was based on expert knowledge from the Protea Atlas Project. We also assumed that all reseeding (in contrast to resprouting) study taxa experience extreme firerelated population fluctuations (Rebelo, 2001). Climate change impacts on species distributions were considered in the application of criteria A and B under the climate change scenarios.

Our program requires the following input data for each taxon: total area and percentage of transformed areas of $\mathrm{EOO}$ and $\mathrm{AOO}$, percentage of range loss between now and 2020 under the climate change scenarios, number of locations (here grid cells occupied) and whether the taxon is a reseeder or resprouter. The data were compiled and computed using ArcGIS software (ESRI ArcGIS Version 8.2) and Arc Macro Language (AML) scripts. First, all GIS layers were projected to an Albers projection with World Geodetic System 1984 datum. Second, we generated species- specific layers of the EOO by drawing the smallest possible circumscribing polygon around the species localities for current and future species distributions (IUCN, 2001), which were beforehand buffered by $500 \mathrm{~m}$ to adjust for potential locality pseudoreplicates arising from the strategy of temporal resampling (Pressey et al., 2003). Third, we generated speciesspecific layers of the AOO by selecting only those cells of a $1 \mathrm{~min}$ grid containing species localities (IUCN, 2001). Clearly, AOO calculations are scale-dependent (IUCN, 2001; Hartley \& Kunin, 2003; IUCN, 2003), and IUCN (2003) recommends a cell size of $4 \mathrm{~km}^{2}$ for AOO calculations. Here, a $1 \mathrm{~min}$ grid with a cell size of about $2.9 \mathrm{~km}^{2}$ was used because it was considered to be more appropriate for the often restricted and scattered ranges of the Proteaceae and determined by the similar resolution of the land use and climate change data. Finally, the number of locations, total area and percentage of transformed areas of $\mathrm{EOO}$ and $\mathrm{AOO}$ 
were calculated for each taxon for now and 2020. Our program provides the following output data for each taxon: Red List categories and criteria met.

Taxa are classified as Critically Endangered (CR), Endangered (EN) or Vulnerable (VU) if they meet the relevant criteria shown in Table 1. These taxa are collectively referred to as Red List taxa or threatened taxa. Taxa that disappear from all their current localities under the climate change scenarios (i.e. they are expected to eventually become extinct) are listed as Extinct (EX). All remaining taxa are classified as Lower Risk (LR). Uplisting means a taxon is classified as more threatened than before, downlisting means a taxon is classified as less threatened than before.

\section{Results}

Red List status excluding and including future threats: general trends

For this study, all 227 Proteaceae taxa endemic to the CFR for which there were species-specific climate change predictions available were selected. If future threats are excluded from the Red List assessment there are $101 \mathrm{LR}, 37 \mathrm{VU}, 86 \mathrm{EN}$ and three CR taxa among them (Table 2). According to our simulations, the current Red List status of the majority of study taxa does not change if future threats as predicted for 2020 are included in the assessment (Fig. 4a). However, between $3.5 \%$ and $29.1 \%$ of the 227 study taxa are uplisted under the future scenarios. Land use change (scenarios $-\mathrm{CC} 1$ to $-\mathrm{CC} 4$ ) triggers uplistings for up to 25 taxa, but climate change (scenarios $+\mathrm{CC} 1$ to $+\mathrm{CC} 4$ ) triggers uplistings of up to three threat categories for up to 66 taxa (Table 2). Whereas $55.5 \%$ of the study taxa are classified as threatened (CR, EN or VU) if future threats are excluded from the assessment, $57.3 \%$ and $71.8 \%$ are listed as threatened or EX under the future best(-CC1) and worst-case ( + CC4) scenarios, respectively (Fig. 4b).

With increasing severity of the future scenarios (i.e. towards high habitat transformation, low habitat conservation and including climate change impacts) (Fig. 2), the number of LR taxa decreases from 101 to 64 if future threats are included (Table 2). In contrast, the number of EX and CR taxa increases, particularly under the climate change scenarios, to four and 16, respectively, while the number of EN taxa rises from 86 to 101 under the worst-case scenario ( + CC4). Generally, high future habitat conservation (i.e. expansion of the existing reserve network by the three proposed megareserves) has almost no effect on the Red List status of the study taxa (only Serruria fasciflora is once listed as VU instead of EN with high conservation instead of low conservation), whereas high future habitat transformation has a major effect on the number of EN taxa. Climate change is, however, responsible for the majority of EX and CR listings.

Surprisingly, four taxa are downlisted under at least one of the climate change scenarios (Fig. 4a): Leucadendron muirii, Protea acuminata, Protea recondita and

Table 2 Overview showing for 227 modelled Proteaceae taxa of the Cape Floristic Region: Number of taxa uplisted (2-3 cat.: only those uplisted by two or three Red List categories), number of taxa per Red List category and Red List criteria met for Red List taxa, if future threats as predicted for 2020 are either excluded (present) or included in the Red List assessment (scenarios increase in severity from top to bottom: $-\mathrm{CC}$ is without climate change; + CC is with climate change)

\begin{tabular}{|c|c|c|c|c|c|c|c|c|c|c|c|c|c|}
\hline & \multirow[b]{2}{*}{ Taxa } & \multirow{2}{*}{$\begin{array}{l}\text { Uplisted } \\
\text { taxa }\end{array}$} & \multirow{2}{*}{$\begin{array}{l}\text { Uplisted taxa } \\
(2-3 \text { cat. })\end{array}$} & \multicolumn{5}{|c|}{$\begin{array}{l}\text { Number of taxa per Red List } \\
\text { category }\end{array}$} & \multicolumn{4}{|c|}{$\begin{array}{l}\text { Red List criteria met for } \\
\text { Red List taxa }\end{array}$} & \multirow{2}{*}{$\begin{array}{l}\text { Average number } \\
\text { of criteria met }\end{array}$} \\
\hline & & & & LR & VU & $\mathrm{EN}$ & CR & EX & A3 & $\mathrm{A} 2 / 4$ & B1 & B2 & \\
\hline Present & 227 & - & - & 101 & 37 & 86 & 3 & 0 & 0 & 61 & 87 & 89 & 1.88 \\
\hline$-\mathrm{CC} 1$ & 227 & 8 & 1 & 97 & 37 & 88 & 5 & 0 & 0 & 66 & 85 & 86 & 1.82 \\
\hline$-\mathrm{CC} 2$ & 227 & 8 & 1 & 97 & 37 & 88 & 5 & 0 & 0 & 66 & 85 & 86 & 1.82 \\
\hline$-\mathrm{CC} 3$ & 227 & 25 & 8 & 88 & 32 & 101 & 6 & 0 & 0 & 83 & 86 & 89 & 1.86 \\
\hline$-\mathrm{CC} 4$ & 227 & 25 & 8 & 88 & 32 & 101 & 6 & 0 & 0 & 86 & 86 & 89 & 1.88 \\
\hline + CC1 & 227 & 54 & 15 & 71 & 49 & 88 & 15 & 4 & 63 & 54 & 75 & 80 & 1.79 \\
\hline$+\mathrm{CC} 2$ & 227 & 54 & 15 & 71 & 49 & 88 & 15 & 4 & 63 & 54 & 75 & 80 & 1.79 \\
\hline$+\mathrm{CC} 3$ & 227 & 65 & 21 & 64 & 43 & 100 & 16 & 4 & 60 & 67 & 79 & 87 & 1.84 \\
\hline$+\mathrm{CC} 4$ & 227 & 66 & 21 & 64 & 42 & 101 & 16 & 4 & 59 & 70 & 79 & 86 & 1.85 \\
\hline
\end{tabular}

The different future scenarios are listed in Fig. 2. The Red List categories are Extinct (EX), Critically Endangered (CR), Endangered (EN), Vulnerable (VU) and Lower Risk (LR). The Red List criteria are listed in Table 1. More than one criterion was frequently met for an individual taxon justifying the assigned category: the last column shows the average number of Red List criteria met per Red List taxon. 
(a)
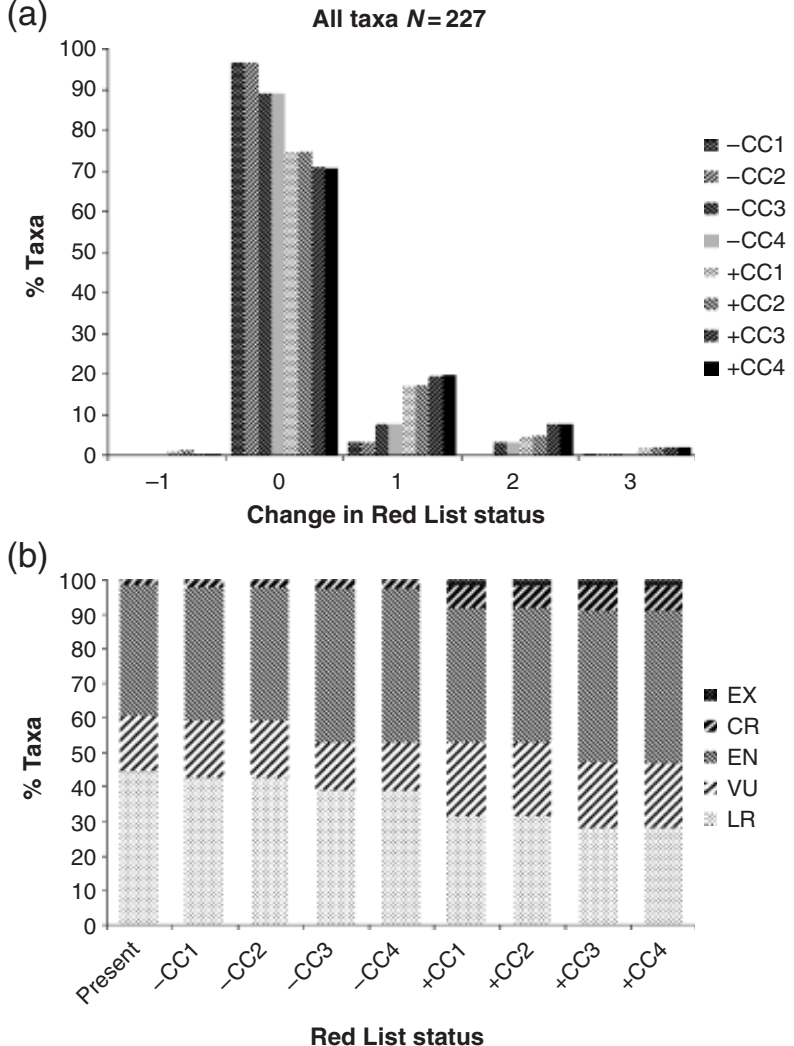

Fig. 4 (a) Change (number of categories downlisted or uplisted) in Red List status from a Red List assessment excluding future threats to one including future threats as predicted for 2020. (b) Red List status for 227 modelled Proteaceae taxa of the Cape Floristic Region if future threats as predicted for 2020 are either excluded (present) or included in the Red List assessment (scenarios increase in severity from left to right: $-\mathrm{CC}$ is without climate change; + CC is with climate change). The different future scenarios are listed in Fig. 2.

Serruria effusa. These taxa are downlisted because their smaller future ranges are relatively less transformed than their current ones while the reductions in range size are too small to affect their Red List status.

\section{Taxa with highest threat status}

Of the 20 taxa listed as CR or EX under any of the future scenarios (Table 2), climate change-induced range losses ( + CC1 to + CC4) cause the critical endangerment of 11 taxa and the extinction of four taxa, namely Leucadendron brunioides var. flumenlupinum, Leucadendron thymifolium, Leucospermum arenarium and Protea longifolia var. minor (Table 3). In addition, low habitat transformation (-CC1 and $-\mathrm{CC} 2$ ) triggers the uplisting of two taxa into the CR category, with high habitat transformation (-CC3 and $-\mathrm{CC} 4)$ adding another. The remaining two taxa are already listed as CR if future threats are excluded and do not change their Red List status under any of the future scenarios. There is a geographic bias in the 20 taxa with $70 \%$ occurring on the West Coast and in the Southwest, whereas only 30\% are from the South Central and Northwest.

\section{Taxa with largest changes in threat status}

In total, there are 22 different taxa that are uplisted by two or three Red List categories under at least one of the future scenarios (Fig. 4a). It is noteworthy that all threats can individually result in such uplistings. For example, Diastella thymelaeoides subsp. meridiana is a taxon from the Southwest that is uplisted from LR to CR under the best-case scenario $(-\mathrm{CC} 1)$ and all other future scenarios (Table 3). On the other hand, the Red List status of taxa such as Leucadendron 'touwsrivierenses' (undescribed species) and Leucospermum spathulatum is only affected under the climate change scenarios ( + CC1 to + CC4) (Table 3). Overall, climate change causes 16 of the highest uplistings, four times acting in concert with high habitat transformation, while high and low habitat transformation alone trigger five and one of the highest uplistings, respectively. Of the 22 different taxa, $82 \%$ are from the South Central and Southwest, and only 9\% each from the West Coast and Northwest.

\section{Which Red List criteria determined the Red List status of threatened taxa?}

On average, nearly two (1.84) of the four Red List criteria applied here concurrently determined a threatened taxon's Red List status (Table 2). The total number of criteria met rises with increasing severity of the future scenarios. The geographic range criteria B1 and B2 were met the most, but with increasing severity of the future scenarios the population reduction criteria A3 and A4 were met increasingly. Criterion A3 indicates climate change impacts, whereas criterion A4 indicates land use change impacts (Table 1). Comparing the relative importance of these future threats based on Table 2 is difficult as both land use and climate change affect criterion $B$.

\section{How are taxa from different regions affected?}

Overall, the Proteaceae in the Southwest and, in particular, on the West Coast are more threatened than those in the South Central and Northwest (Fig. 5a). On the West Coast, the number of EX and CR taxa rises from $9.5 \%$ if future threats are excluded to $38.1 \%$ under the worst-case scenario ( + CC4), and at least $90.5 \%$ of the taxa are classified as threatened or EX in any case. 
Table 3 All taxa that are listed as Extinct (EX) or Critically Endangered (CR) of 227 modelled Proteaceae taxa of the Cape Floristic Region if future threats as predicted for 2020 are either excluded (present) or included in the Red List assessment (scenarios increase in severity from left to right: $-\mathrm{CC}$ is without climate change; + CC is with climate change)

\begin{tabular}{|c|c|c|c|c|c|c|c|}
\hline \multirow[b]{3}{*}{ Taxon } & \multirow[b]{3}{*}{ Present } & \multicolumn{4}{|c|}{ Future scenarios } & \multirow[b]{3}{*}{ Cause } & \multirow[b]{3}{*}{ Region } \\
\hline & & $-\mathrm{CC} 1$ & $-\mathrm{CC} 3$ & $+\mathrm{CC} 1$ & $+\mathrm{CC} 3$ & & \\
\hline & & $-\mathrm{CC} 2$ & $-\mathrm{CC} 4$ & $+\mathrm{CC} 2$ & $+\mathrm{CC} 4$ & & \\
\hline Diastella proteoides & EN & EN & EN & CR & CR & $\mathrm{CC}$ & West Coast \\
\hline Diastella thymelaeoides subsp. meridiana & LR & CR & CR & CR & CR & LT & Southwest \\
\hline Leucadendron argenteum & EN & CR & CR & CR & CR & LT & Southwest \\
\hline Leucadendron brunioides var. flumenlupinum & EN & EN & EN & EX & EX & $\mathrm{CC}$ & West Coast \\
\hline Leucadendron levisanus & EN & EN & CR & EN & CR & HT & West Coast \\
\hline Leucadendron remotum & EN & EN & EN & CR & CR & $\mathrm{CC}$ & Northwest \\
\hline Leucadendron stellare & CR & CR & CR & CR & CR & - & West Coast \\
\hline Leucadendron stelligerum & EN & EN & $\mathrm{EN}$ & CR & CR & $\mathrm{CC}$ & Southwest \\
\hline Leucadendron thymifolium & CR & CR & CR & EX & EX & $\mathrm{CC}$ & West Coast \\
\hline Leucadendron 'touwsrivierenses' (undescribed sp.) & LR & LR & LR & CR & CR & $\mathrm{CC}$ & South Central \\
\hline Leucospermum arenarium & EN & EN & EN & EX & EX & $\mathrm{CC}$ & West Coast \\
\hline Leucospermum conocarpodendron subsp. conocarpodendron & CR & CR & CR & CR & $\mathrm{CR}$ & - & Southwest \\
\hline Leucospermum muirii & EN & EN & EN & CR & CR & $\mathrm{CC}$ & South Central \\
\hline Leucospermum parile & EN & EN & EN & CR & CR & $\mathrm{CC}$ & West Coast \\
\hline Leucospermum patersonii & EN & EN & EN & CR & CR & $\mathrm{CC}$ & Southwest \\
\hline Leucospermum spathulatum & LR & LR & LR & CR & CR & $\mathrm{CC}$ & Northwest \\
\hline Paranomus abrotanifolius & EN & EN & EN & CR & CR & $\mathrm{CC}$ & South Central \\
\hline Protea convexa & LR & LR & LR & CR & CR & $\mathrm{CC}$ & South Central \\
\hline Protea longifolia var. minor & EN & EN & EN & EX & EX & $\mathrm{CC}$ & Southwest \\
\hline Serruria linearis & EN & EN & EN & CR & CR & $\mathrm{CC}$ & West Coast \\
\hline
\end{tabular}

The different future scenarios are listed in Fig. 2. The other Red List categories are Endangered (EN), Vulnerable (VU) and Lower Risk (LR). The causes of uplistings are climate change (CC), high habitat transformation (HT) and low habitat transformation (LT).

In the Southwest, up to $92.5 \%$ of the taxa are either threatened or EX under the worst-case scenario ( + CC4), but a few taxa remain in the LR category, and only $6.5 \%$ are classified as EX or CR under the climate change scenarios (+ CC1 to + CC4). In contrast, $51.1 \%$ and $49.2 \%$ of the taxa in the Northwest and South Central remain in the LR category even under the worst-case scenario ( + CC4). Moreover, no extinctions occur in these regions, but $4.4 \%$ of the taxa in the Northwest and $6.6 \%$ of the taxa in the South Central are listed as CR under the climate change scenarios.

\section{How are taxa from different altitudes affected?}

Overall, high-altitude taxa are less threatened than lowaltitude taxa (Fig. 5b). Under the worst-case scenario ( + CC4) for 2020, $94.9 \%$ of the taxa that occur below a mean altitude of $400 \mathrm{~m}$ at present are either threatened or EX, followed by $77.8 \%$ of the taxa between $400-$ $800 \mathrm{~m}$. In contrast, $43.6 \%$ of the taxa between 800 $1200 \mathrm{~m}$ and $71.1 \%$ of the taxa above $1200 \mathrm{~m}$ remain in the LR category. Moreover, all extinctions and 14 out of
16 listings under the $\mathrm{CR}$ category involve taxa from below $400 \mathrm{~m}$. Under the climate change scenarios $(+\mathrm{CC} 1$ to $+\mathrm{CC} 4)$, the largest increases in the proportion of threatened vs. not-threatened taxa occur however above $400 \mathrm{~m}$ in the areas with the least threatened taxa to date. Under the worst-case scenario (+ CC4), the proportion of threatened taxa increases roughly sixfold above $1200 \mathrm{~m}$ and twofold between 800 and $1200 \mathrm{~m}$, whereas below $400 \mathrm{~m}$ it rises only from $88.5 \%$ to $94.9 \%$.

Mapping the distribution of today's vs. tomorrow's threatened taxas

Comparing the mapped distribution of today's vs. tomorrow's threatened taxa (i.e. taxa classified as threatened excluding and including future threats) allows us to identify areas in which the number of these species of concern increases because of future land use and climate change as projected here. We therefore subtracted the number of threatened taxa per grid cell computed by a Red List assessment excluding 
(a)

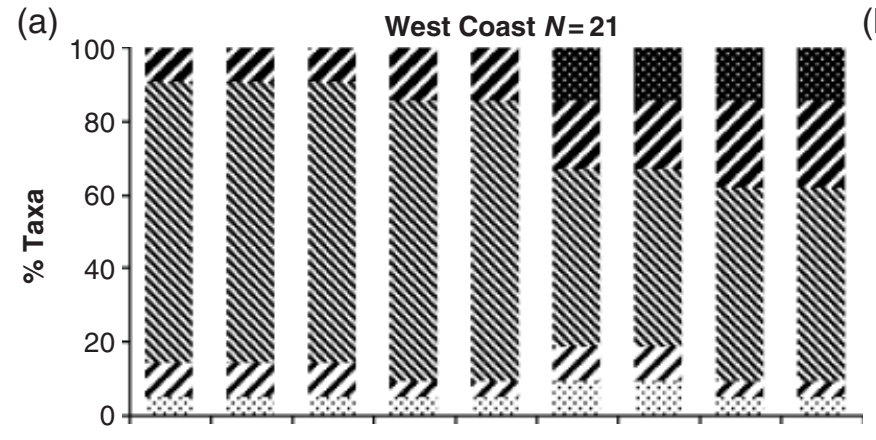

Southwest $N=93$

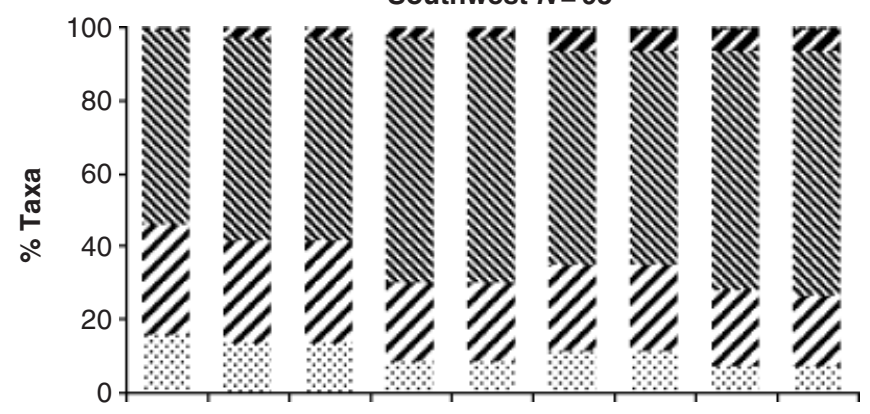

South Central $N=61$

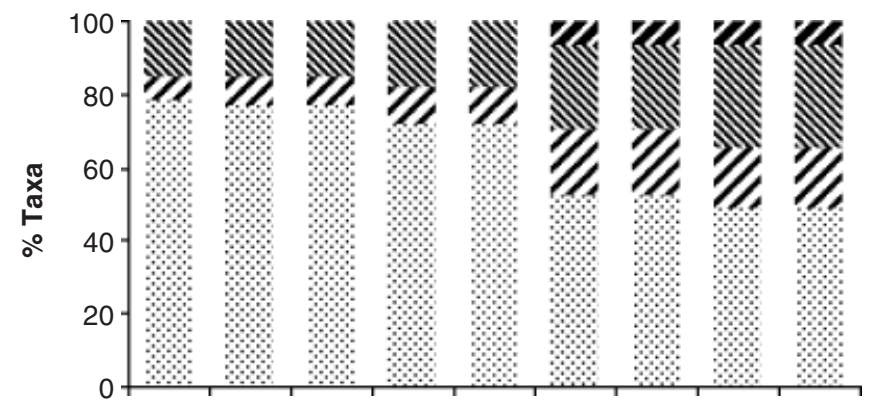

Northwest $N=45$

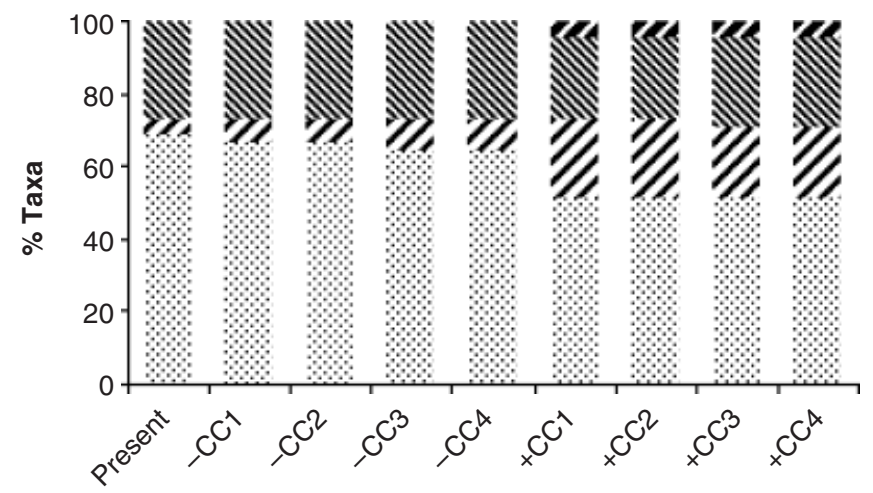

Red List status (b)

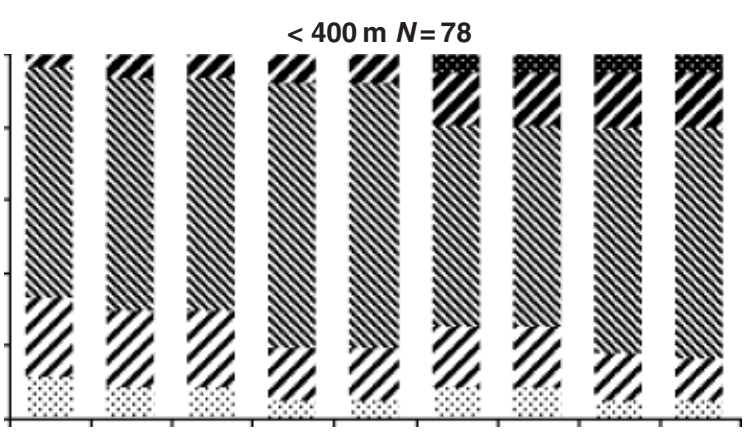

$400-800 \mathrm{~m} \mathrm{~N}=72$

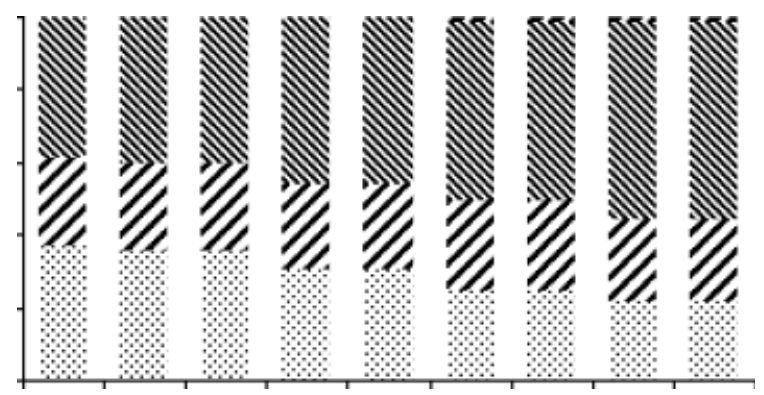

$800-1200$ m N=39

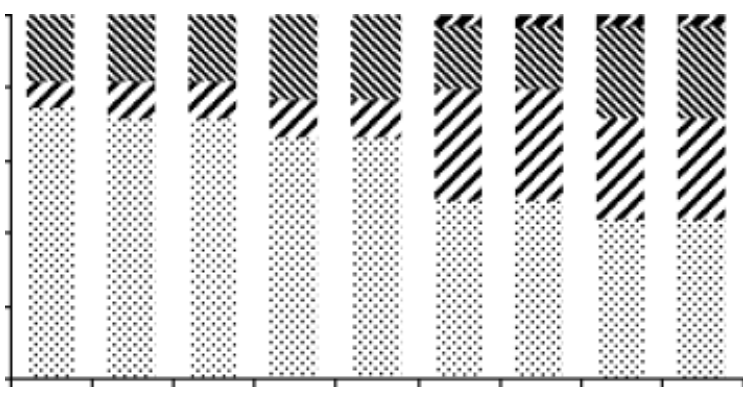

$>1200 \mathrm{~m} \mathrm{~N}=38$

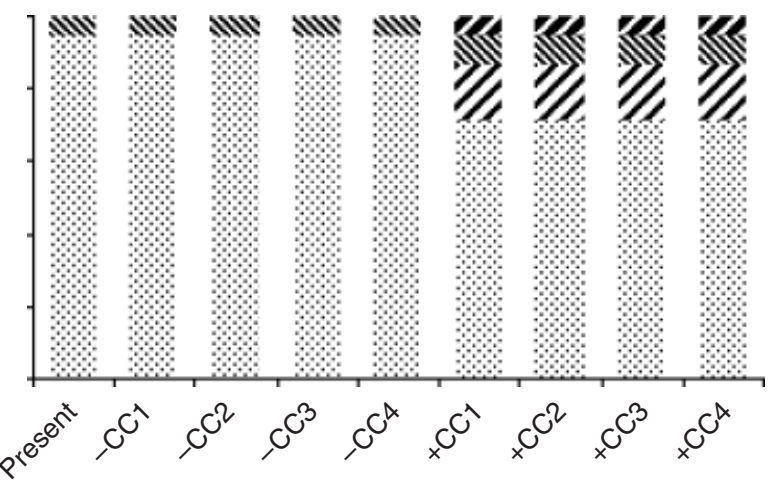

LR ク VU N EN C CR EX

Fig. 5 Red List status for Proteaceae taxa from different regions (a) and altitudes (b) of the Cape Floristic Region if future threats as predicted for 2020 are either excluded (present) or included in the Red List assessment (scenarios increase in severity from left to right: $-\mathrm{CC}$ is without climate change; + CC is with climate change). The different future scenarios are listed in Fig. 2. 
future threats from the number of threatened or EX taxa per grid cell under the future worst-case scenarios with ( + CC4) and without (-CC4) climate change (Fig. 3b, c). Our maps show that, without climate change, the number of threatened taxa increases by up to three taxa per grid cell, with the Cape Peninsula, Pringle Bay area (southeast of Cape Town) and some inland mountain areas most affected by high habitat transformation. In contrast, with climate change, the number of threatened taxa increases by up to eight taxa per grid cell. Considerable changes occur especially in inland mountain areas, and to a lesser extent in coastal mountain areas such as the Cape Peninsula.

\section{Discussion}

For conservation planning and action, it is important to be able to assess how, where and when future threats could affect species persistence. Assessing this should facilitate the required shift from reactive to proactive conservation approaches. Our study estimates how many Proteaceae in the CFR could be affected (as shown by a change in their Red List status) by future threats that are usually not included in current IUCN Red List assessments. This was achieved by incorporating environmental conditions predicted by land use and climate change models for 2020 into a Red List assessment. The timeframe of this study allows us to evaluate our predictions in the near- to medium-term. A particular strength of our approach is the integration of both land use and climate change as major drivers of species endangerment and extinction. Furthermore, we integrated predicted species distributions (i.e. rather hypothetical potential ranges) with actual species distributions to assess future climate change impacts in the real world. Despite its limitations, our study serves as a first estimation of the 'shadow extinction risk' from future land use and climate change not evident in current IUCN Red Lists. The expected changes are substantial, affecting up to $29 \%$ of the 227 taxa, and they differ in their spatial and causal components. Species and regions not considered as threatened if future threats are excluded appear to be severely affected by land use and climate change in the future. Our results could be characteristic for many species and regions in and beyond the CFR (Burgman, 2002). Finally, our approach can in a sense be seen as a test of the value of planned interventions for conservation.

\section{General limitations of our study}

Our study should be seen as a first estimation of what could happen to the Red List status of the Proteaceae in the CFR by 2020. We regard our results as giving a reasonable range of future trends based on our current knowledge of the potential impacts of future land use and climate change on the threat status of the Proteaceae at a regional scale. Our approach utilizes data that introduce uncertainty and, together with our assumptions, models and scenarios, should be interpreted accordingly. Caution should be used if our results are used to infer impacts for other taxa or at other temporal or spatial scales. In the next section we investigate possible reasons for underestimation or overestimation of the impacts of future threats on the Proteaceae.

\section{Reasons for underestimation of the impacts of future threats}

We did not assess some of the highly threatened rangerestricted Proteaceae taxa in the CFR because it was impossible to correctly model their distributions and, thus, there were no species-specific climate change predictions available for them. Hence, our 227 study taxa include less than $10 \%$ of the taxa considered to be CR according to the Protea Atlas Project, which contains records for 377 Proteaceae taxa. All CR taxa are, however, expected to be still highly threatened or more so in 2020, and thus our study may seriously underestimate the overall impacts of future threats. Our study does not include the impacts of future threats other than land use and climate change, but commercial or casual plant harvesting is a serious threat to some of the charismatic Proteaceae (Rebelo, 1992; Cowling et al., 1997). Some of the existing reserves may not persist, and habitat transformation may not be prevented in both the existing reserves and proposed megareserves, as assumed here. For instance, invasive alien plants might further invade existing conservation areas, some of which are already densely invaded (Rouget et al., 2003b). Possible positive feedbacks between land use and climate change (Root et al., 2003; Opdam \& Wascher, 2004) are not considered here. Climate change could however increase the fire frequency and intensity, putting Proteaceae that take up to 15 years to flower for the first time at risk, or change the fire season (Van Wilgen et al., 1992). Climate change may also facilitate alien invasions with implications for indigenous species (Dukes \& Mooney, 1999; McCarty, 2001). The predicted increase in invasive alien grasses in the CFR, for instance, could radically accelerate the fire cycle and, in turn, the extinction risk of the Proteaceae (Richardson et al., 2000; Brooks et al., 2004).

\section{Reasons for overestimation of the impacts of future threats}

We assessed only Proteaceae taxa endemic to the CFR, but more widespread taxa are expected to be less 
threatened according to the Red List criteria. However, over $95 \%$ of Proteaceae are endemic to the CFR (Goldblatt \& Manning, 2002). Most importantly, some plants could persist outside their potential future ranges in the near- to medium-term, because most Proteaceae are relatively long lived and some have long-lived seed banks (Cowling et al., 1997; Rebelo, 2001), resulting in time lags between climate change and species responses. Some Proteaceae may also be more flexible with regard to their bioclimatic and edaphic constraints than assumed in the models (Davis \& Shaw, 2001; Pearson \& Dawson, 2003; Hampe, 2004), and could persist permanently outside their potential future ranges. With increasing atmospheric $\mathrm{CO}_{2}$ concentrations, some Proteaceae may thrive, although the nutrient-poor environments of the CFR are likely to limit plant growth even in a $\mathrm{CO}_{2}$-rich world (Stock \& Midgley, 1995). Some Proteaceae may, both with or without human facilitation, successfully migrate and colonize new areas of their potential future ranges, thereby violating our assumption of no migration. The potential future ranges of about $16 \%$ of the taxa are in fact larger than their potential ranges at present. Potential ranges are however limited predictors of species distributions in the real world (Pearson \& Dawson, 2003) - all Proteaceae occupy far fewer grid cells at present than predicted by their potential ranges, and an actual range expansion requires successful migration and colonization. However, many Proteaceae will have problems with 'keeping up with climate change' because of their limited dispersal ability compared with the rate at which the climate is predicted to change (Schurr et al., 2004). Habitat fragmentation is a further obstacle to migration in the CFR (Rouget et al., 2003c), and invasive alien plants, which are better dispersers, are likely to increasingly outcompete the indigenous Proteaceae (Richardson et al., 2000). Habitat transformation in species ranges may however not necessarily result in population declines, as assumed here, and indigenous Proteaceae could persist without notable population declines in areas only moderately invaded by invasive alien plants (Latimer et al., 2004). Except for the proposed megareserves no other future conservation actions were considered here. The existing reserve network in the CFR is, however, likely to be continuously enlarged and enhanced not only by the proposed megareserves, increasingly meeting the needs of threatened species (Cowling et al., 2003; Rouget et al., 2003b). Finally, lessons drawn from our study and others should lead to appropriate conservation action that may prevent some of the potential impacts of land use and climate change predicted here.
Implications of our study for the IUCN Red List Categories and Criteria

Comparing the Red List status of the Proteaceae excluding and including future threats highlights how many more threatened species could potentially be found in the CFR if we consider future threats to biodiversity. We suggest that the consideration of future threats is underutilized in current IUCN Red List assessments (Burgman, 2002), although the Red List criteria explicitly allow for this (IUCN, 2001, 2003). For proactive conservation planning and action, this information could be vital, but a lack of data or uncertainty about future threats may be reasons for not considering them. The introduction of a separate Red List reporting criterion for species potentially affected by future threats, particularly climate change, could be a solution to this problem. Our methodology needs to be further developed, but it could provide a first protocol for how to assess potential impacts of future threats.

We generally consider the IUCN Red List Categories and Criteria sensitive enough to detect changes in the threat status of species. It has been noticed, however, that changes in the threat status of species are often caused by changes in the knowledge of taxonomic classification or geographic distribution rather than actual changes in extinction risk (Burgman, 2002; Possingham et al., 2002; Donaldson, 2004), which is not the case in our study. Both the interdependent nature and clear-cut thresholds of some Red List criteria, and our simplistic, computer-based Red Listing approach could however mask more subtle changes than the ones reported here. It is not easy to identify whether this would be because of flaws in our Red Listing approach or in the Red List criteria. The application of criterion $\mathrm{A}$, which requires information on population reduction over specific timeframes (IUCN, 2001, 2003), poses probably the biggest problem, as detailed spatiotemporal information on the history of habitat transformation is lacking. This is probably the case in many parts of the world. In the absence of alternatives, it is also difficult to determine whether or not the proportion of transformed areas in species ranges is an appropriate surrogate for population reduction under the criteria $\mathrm{A}$ and $\mathrm{B}$.

The variability and uncertainty of most species data make consistent Red List assessments already difficult (Akçakaya et al., 2000). Incorporating future threats into Red List assessments adds further uncertainty, which is linked to the land use and climate change predictions, for instance. Nonetheless, it has been suggested that an index of threat be added to the Red List criteria, for example human population density (Harcourt \& Parks, 
2003). According to McKee et al. (2003), the number of threatened mammal and bird species in an average nation is expected to increase by $7 \%$ by 2020 , as predicted by human population growth alone. According to our study, the proportion of threatened Proteaceae taxa could rise on average by $9.3 \%$ (range 1.8$16.3 \%$ ) in the CFR by 2020. These numbers cannot be compared, because they are derived from different indicators of future threats, for instance. It is also important to note that the crude number of threatened vs. not-threatened species can mask significant changes within the threat categories. For South Africa, McKee et al. (2003) predict, in fact, downlistings of mammals and birds because of a projected national human population decline, but admit that continuing land use and climate change cast doubt on this prediction. On a local scale, human population will still continue to grow in areas such as Cape Town, where many threatened plants occur (Rebelo, 1992; Richardson et al., 1996).

Both approaches highlight the desire to foresee future changes in the threat status of species (Manne \& Pimm, 2001). Our study should inspire both the Red Listing and modelling community to further explore such approaches. For risk assessments of other taxa and regions, it would be vital to identify basic criteria of future endangerment and extinction, particularly as it is unlikely that species-specific models such as ours will ever be available for all taxa and regions. Our study highlights however that future threats - particularly when acting in concert - affect even Proteaceae with common characteristics so differently, that it is difficult to generalize our results based on species distributions, for example. Comparable studies, addressing this question in a more formal framework, are required not only for Proteaceae but also other taxa and regions to allow for generalizations. Finally, anticipating future threats to biodiversity should not only improve current risk assessments, but also our ability to take appropriate conservation action now, and thus the new Red List for southern African Proteaceae, which is currently being compiled, takes into account our results.

\section{Applications of our study in conservation planning and action}

This study is currently our best estimation of how the Red List status of the Proteaceae in the CFR could change in the near- to medium-term. Thus, it should be considered cautiously in conservation planning and action. The Proteaceae have been widely used for conservation planning in the CFR (Rebelo \& Siegfried, 1992; Cowling et al., 2003). Recently, retention targets were formulated for the Proteaceae, taking into account the future threats from agriculture, alien plant invasions and urbanization (Pressey et al., 2003). It would also be desirable to integrate spatially explicit information on climate change impacts such as range shifts and losses into conservation planning and reserve siteselection (Araújo et al., 2004; Pyke et al., 2005; Williams et al., 2005). Range shifts and losses could considerably change the distributions of the Proteaceae and, in turn, their sensitivity to the impacts of 'conventional' threats (Opdam \& Wascher, 2004; Hannah et al., 2005).

Conservation planning and action requires the prioritization of species and regions of concern for reserve site-selection, scheduling and monitoring conservation efforts (Margules \& Pressey, 2000). Information on where the number of threatened species increases because of future land use and climate change could be integrated into conservation planning as an additional GIS layer. Monitoring should be focused on Proteaceae that are expected to face the highest threat status or the largest changes in threat status, including the four taxa that are predicted to become extinct. Some of these taxa are not considered as species of concern according to current Red List assessments, which usually do not include future threats, but this will change with the new Red List for southern African Proteaceae. Low-altitude regions along the coast should be prioritized for conservation because they host more of the potentially most threatened species than highaltitude regions in the interior. Required migration distances (i.e. the distances that taxa have to migrate to reach their potential future ranges in a changing climate) are longer in flat, coastal areas than in mountain areas, where steeper climatic gradients prevail. This is particularly worrying as low-lying coastal areas already host the vast majority of threatened Proteaceae (Rebelo, 1992; Richardson et al., 1996). Information such as that provided here on species and regions of concern are useful for the establishment of early warning systems. Threatened species profiling (i.e. the identification of common biological and ecological characteristics of threatened species) may further improve our understanding of combinations of traits and threats that predispose species to endangerment and extinction (Trinder-Smith et al., 1996; Purvis et al., 2000; Manne \& Pimm, 2001).

When it comes to conservation action, the question is: where, and when, to start with which species? Our results may not only assist in locating and scheduling actions through prioritization, but also in detecting the most appropriate actions for certain species and regions, because they indicate the likely causes of future endangerment and extinction. For example, Diastella thymelaeoides subsp. meridiana is uplisted from LR to CR even with low habitat transformation but is 
not further affected by high habitat transformation and climate change (Table 3). Therefore, systematic habitat conservation in its current geographic range appears to be an appropriate action for this taxon. On the other hand, Leucadendron brunioides var. flumenlupinum is only affected by climate change, being uplisted from EN to EX under the climate change scenarios (Table 3), because at present it occurs outside of its potential future range. For this taxon, translocation from its current localities to its potential future range could be considered as an appropriate action to avoid its future extinction (Rutherford et al., 1999). In practice, implications for the biodiversity in the target area have to be examined first, however (Rutherford et al., 1999), to avoid adverse effects such as the hybridization of sister taxa, in this case with Leucadendron brunioides var. brunioides. This study should be used to pilot intervention strategies for Proteaceae predicted to be affected by climate change. Lessons drawn from monitoring and intervening, through translocation, species predicted here to be most affected, should be used to determine whether modelling future climate change impacts is useful for conservation.

Surprisingly, the three proposed megareserves ameliorate the threat status of only one taxon, which severely questions their importance for the conservation of Proteaceae. The megareserves coincide only marginally with the current distributions of the Proteaceae, and most of their newly conserved areas will be in the lowlands of the interior, whereas in these regions most of the Proteaceae are concentrated in the uplands. Therefore, other measures than the successful implementation of these megareserves are required for the Proteaceae. This does however not discredit the importance of the megareserve approach for other biodiversity patterns and processes (Cowling et al., 1999; Younge, 2000; Rouget et al., 2003a), some of which have not been considered at all in previous conservation planning, in contrast to the Proteaceae. Upland Proteaceae are less threatened at present because the mountain areas are less transformed and more conserved (Rouget et al., 2003b, c). Lowland Proteaceae, in contrast, occur largely along the coasts and around Cape Town, where high human population densities, more fragmented and transformed areas, and less conservation areas are concentrated (Richardson et al., 1996). Isolated reserves without latitudinal or altitudinal gradients and corridors, or without cautious translocation strategies, will not be a sustainable solution for the conservation of Proteaceae severely affected by climate change (Halpin, 1997; Hannah et al., 2005). Given that climate change appears to cause significant changes in the Red List status of the Proteaceae, climate change-integrated conservation strategies involving local mitigation and adaptation measures are as much needed as global actions such as the reduction of greenhouse gas emissions (Hannah et al., 2002a, b).

\section{Acknowledgements}

We are particularly grateful to Walter Smit for his help with the GIS analysis. Wendy Foden and Mark Keith provided valuable comments. We are grateful for comments received from David Keith and two anonymous reviewers on earlier versions of this manuscript. The South African National Biodiversity Institute kindly provided its excellent facilities for this project. We especially thank the Protea Atlas Project for providing data sets and programmes. We thank the Western Cape Nature Conservation Board for providing data sets. D. M. R. acknowledges support from the DST/NRF Centre of Excellence for Invasion Biology. G. F. M. acknowledges support from Conservation International's Center for Applied Biodiversity Science and the UNEP/WMO/IPCC AIACC initiative funded by GEF. The DAAD German Academic Exchange Service generously funded B. B.

\section{References}

Akçakaya HR, Ferson S, Burgman MA et al. (2000) Making consistent IUCN classifications under uncertainty. Conservation Biology, 14, 1001-1013.

Araújo MB, Cabeza M, Thuiller W et al. (2004) Would climate change drive species out of reserves? An assessment of existing reserve-selection methods. Global Change Biology, 10, 1618-1626.

Brooks ML, D'Antonio CM, Richardson DM et al. (2004) Effects of invasive alien plants on fire regimes. BioScience, 54, 677-688.

Burgman MA (2002) Are listed threatened plant species actually at risk? Australian Journal of Botany, 50, 1-13.

Cowling RM, Pressey RL, Lombard AT et al. (1999) Framework for a conservation plan for the Cape Floristic Region. Report 9902, Institute for Plant Conservation, Cape Town.

Cowling RM, Pressey RL, Rouget M et al. (2003) A conservation plan for a global biodiversity hotspot - the Cape Floristic Region, South Africa. Biological Conservation, 112, 191-216.

Cowling RM, Richardson DM, Mustart PJ (1997) Fynbos. In: Vegetation of Southern Africa (Cowling RM, Richardson DM, Pierce SM, eds), pp. 99-130. Cambridge University Press, Cambridge.

Czech B, Krausman PR (1997) Distribution and causation of species endangerment in the United States. Science, 277, 11161117.

Davis MB, Shaw RG (2001) Range shifts and adaptive responses to Quaternary climate change. Science, 292, 673-679.

Donaldson JS (2004) Saving ghosts? The implications of taxonomic uncertainty and shifting infrageneric concepts in the cycadales for red listing and conservation planning. In: Cycad Classification: Concepts and Recommendations (Walters T, Osborne R, eds), pp. 13-22. CABI Publishing, Wallingford.

Dukes JS, Mooney HA (1999) Does global change increase the success of biological invaders? Trends in Ecology and Evolution, 14, 135-139. 
Gärdenfors U, Hilton-Taylor C, Mace GM et al. (2001) The application of IUCN Red List criteria at regional levels. Conservation Biology, 15, 1206-1212.

Gaston KJ, Blackburn TM, Goldewijk KK (2003) Habitat conversion and global avian biodiversity loss. Proceedings of the Royal Society London B, 270, 1293-1300.

Goldblatt P, Manning JC (2002) Plant diversity of the Cape region of southern Africa. Annals of the Missouri Botanical Garden, 89, 281-302.

Halpin PN (1997) Global climate change and natural-area protection: management responses and research directions. Ecological Applications, 7, 828-843.

Hampe A (2004) Bioclimate envelope models: what they detect and what they hide. Global Ecology and Biogeography, 13, 469-471.

Hannah L, Midgley GF, Hughes GO et al. (2005) The view from the Cape: extinction risk, protected areas, and climate change. BioScience, 55, 231-242.

Hannah L, Midgley GF, Lovejoy T et al. (2002a) Conservation of biodiversity in a changing climate. Conservation Biology, 16, 264-268.

Hannah L, Midgley GF, Millar D (2002b) Climate changeintegrated conservation strategies. Global Ecology and Biogeography, 11, 485-495.

Harcourt AH, Parks SA (2003) Threatened primates experience high human densities: adding an index of threat to the IUCN Red List criteria. Biological Conservation, 109, 137-149.

Hartley S, Kunin WE (2003) Scale dependency of rarity, extinction risk, and conservation priority. Conservation Biology, 17, 1559-1570.

Hoffman MT (1997) Human impacts on vegetation. In: Vegetation of Southern Africa (Cowling RM, Richardson DM, Pierce SM, eds), pp. 507-534. Cambridge University Press, Cambridge.

Hughes L (2000) Biological consequences of global warming: is the signal already apparent? Trends in Ecology and Evolution, 15, 56-61.

IUCN (2001) IUCN Red List Categories and Criteria: Version 3.1. IUCN Species Survival Commission, IUCN, Gland and Cambridge.

IUCN (2003) Guidelines for Using the IUCN Red List Categories and Criteria. IUCN Species Survival Commission, IUCN, Gland and Cambridge.

Lamoreux J, Akçakaya HR, Bennun L et al. (2003) Value of the IUCN Red List. Trends in Ecology and Evolution, 18, 214-215.

Latimer AM, Silander JA, Gelfand AE et al. (2004) A method for quantifying the magnitude of threat to plant biodiversity from alien plant invasions and other anthropogenic factors - a case study in the Cape Floristic Region, South Africa. South African Journal of Science, 100, 81-86.

Lloyd JW, van den Berg EC, van Wyk E (1999) CAPE project: the mapping of threats to biodiversity in the Cape Floristic Region with the aid of remote sensing and geographic information systems. Report GW/A1999/54, Institute for Soil, Climate and Water, Agricultural Research Council, Pretoria.

Lombard AT, Cowling RM, Pressey RL et al. (2003) Effectiveness of land classes as surrogates for species in conservation planning for the Cape Floristic Region. Biological Conservation, $112,45-62$.
Manne LL, Pimm SL (2001) Beyond eight forms of rarity: which species are threatened and which will be next? Animal Conservation, 4, 221-229.

Margules CR, Pressey RL (2000) Systematic conservation planning. Nature, 405, 243-253.

McCarty JP (2001) Ecological consequences of recent climate change. Conservation Biology, 15, 320-331.

McKee JK, Sciulli PW, Fooce CD et al. (2003) Forecasting global biodiversity threats associated with human population growth. Biological Conservation, 115, 161-164.

Midgley GF, Hannah L, Millar D et al. (2002) Assessing the vulnerability of species richness to anthropogenic climate change in a biodiversity hotspot. Global Ecology and Biogeography, 11, 445-451.

Midgley GF, Hannah L, Millar D et al. (2003) Developing regional and species-level assessments of climate change impacts on biodiversity in the Cape Floristic Region. Biological Conservation, 112, 87-97.

Myers N, Mittermeier RA, Mittermeier CG et al. (2000) Biodiversity hotspots for conservation priorities. Nature, 403 , 853-858.

Opdam P, Wascher D (2004) Climate change meets habitat fragmentation: linking landscape and biogeographical scale levels in research and conservation. Biological Conservation, 117, 285-297.

Parmesan C, Yohe G (2003) A globally coherent fingerprint of climate change impacts across natural systems. Nature, 421, $37-42$.

Pearce J, Ferrier S (2000) An evaluation of alternative algorithms for fitting species distribution models using logistic regression. Ecological Modelling, 128, 127-147.

Pearson RG, Dawson TP (2003) Predicting the impacts of climate change on the distribution of species: are bioclimate envelope models useful? Global Ecology and Biogeography, 12, 361-371.

Pearson RG, Dawson TP, Liu C (2004) Modelling species distributions in Britain: a hierarchical integration of climate and land-cover data. Ecography, 27, 285-298.

Possingham HP, Andelman SJ, Burgman MA et al. (2002) Limits to the use of threatened species lists. Trends in Ecology and Evolution, 17, 503-507.

Pressey RL, Cowling RM, Rouget M (2003) Formulating conservation targets for biodiversity pattern and process in the Cape Floristic Region, South Africa. Biological Conservation, 112, 99-127.

Purvis A, Gittleman JL, Cowlishaw G et al. (2000) Predicting extinction risk in declining species. Proceedings of the Royal Society London B, 267, 1947-1952.

Pyke CR, Andelman S, Midgley GF (2005) Identifying priority areas for bioclimatic representation under climate change: a case study for Proteaceae in the Cape Floristic Region, South Africa. Biological Conservation, in press.

Rebelo AG (1992) Red data book species in the Cape Floristic Region: threats, priorities and target species. Transactions of the Royal Society of South Africa, 48, 55-86.

Rebelo AG (2001) Proteas: A Field Guide to the Proteas of Southern Africa. Fernwood Press, Cape Town.

Rebelo AG, Siegfried WR (1992) Where should nature reserves be located in the Cape Floristic Region, South Africa? Models 
for the spatial configuration of a reserve network aimed at maximizing the protection of floral diversity. Conservation Biology, 6, 243-252.

Richardson DM, Bond WJ, Dean WRJ et al. (2000) Invasive alien organisms and global change: a South African perspective. In: Invasive Species in a Changing World (Mooney HA, Hobbs RJ, eds), pp. 303-349. Island Press, Washington.

Richardson DM, van Wilgen BW, Higgins SI et al. (1996) Current and future threats to plant biodiversity on the Cape Peninsula, South Africa. Biodiversity and Conservation, 5, 607-647.

Root TL, Price JT, Hall KR et al. (2003) Fingerprints of global warming on wild animals and plants. Nature, 421, $57-60$.

Rouget M, Cowling RM, Pressey RL et al. (2003a) Identifying spatial components of ecological and evolutionary processes for regional conservation planning in the Cape Floristic Region, South Africa. Diversity and Distributions, 9, 191-210.

Rouget M, Richardson DM, Cowling RM (2003b) The current configuration of protected areas in the Cape Floristic Region, South Africa - reservation bias and representation of biodiversity patterns and processes. Biological Conservation, 112, 129-145.

Rouget M, Richardson DM, Cowling RM et al. (2003c) Current patterns of habitat transformation and future threats to biodiversity in terrestrial ecosystems of the Cape Floristic Region, South Africa. Biological Conservation, 112, 63-85.

Rutherford MC, Midgley GF, Bond WJ et al. (1999) Plant Biodiversity: Vulnerability and Adaptation Assessment. South African Country Study on Climate Change, Department of Environmental Affairs and Tourism, Pretoria.

Sala OE, Chapin FS, Armesto JJ et al. (2000) Global biodiversity scenarios for the year 2100. Science, 287, 1770-1774.

Schurr F, Higgins SI, Bond WJ et al. (2004) Can South African Proteaceae keep up with climate change? In: Southern Temperate Ecosystems and Biota: Contributions towards a Global Synthesis, Proceedings of the 4th Southern Connections Conference, 19-23 January 2004 (Midgley J, Bond WJ, eds), University of Cape Town, Cape Town.
Stock WD, Midgley GF (1995) Ecosystem response to elevated $\mathrm{CO}_{2}$ : nutrient availability and nutrient cycling. In: Global Change and Mediterranean-Type Ecosystems (Moreno JM, Oechel WC, eds), pp. 326-342. Springer, New York.

Thomas CD, Cameron A, Green RE et al. (2004) Extinction risk from climate change. Nature, 427, 145-148.

Thuiller W (2004) Patterns and uncertainties of species' range shifts under climate change. Global Change Biology, 10, 20202027.

Thuiller W, Araújo MB, Lavorel S (2003) Generalized models vs. classification tree analysis: predicting spatial distributions of plant species at different scales. Journal of Vegetation Science, 14, 669-680.

Thuiller W, Araújo MB, Pearson RG et al. (2004) Uncertainty in predictions of extinction risk. Nature, 430, 34.

Trinder-Smith TH, Cowling RM, Linder HP (1996) Profiling a besieged flora: endemic and threatened plants of the Cape Peninsula, South Africa. Biodiversity and Conservation, 5, 575589.

Van Wilgen BW, Bond WJ, Richardson DM (1992) Ecosystem management. In: The Ecology of Fynbos: Nutrients, Fire and Diversity (Cowling RM, ed.), pp. 345-371. Oxford University Press, Cape Town

White D, Minotti PG, Barczak MJ et al. (1997) Assessing risks to biodiversity from future landscape change. Conservation Biology, 11, 349-360.

Wilcove DS, Rothstein D, Dubow J et al. (1998) Quantifying threats to imperiled species in the United States. BioScience, 48, 607-615.

Williams PH, Hannah L, Andelman SJ et al. (2005) Planning for climate change: identifying minimum-dispersal corridors for the Cape Proteaceae. Conservation Biology, in press.

Yee TW, Mitchell ND (1991) Generalized additive models in plant ecology. Journal of Vegetation Science, 2, 587-602.

Younge A (2000) Cape Action Plan for the Environment: A Biodiversity Strategy and Action Plan for the Cape Floral Kingdom. WWF South Africa, Stellenbosch. 